\title{
CHARACTERISTICS OF THE ULTRAPHYTOPLANKTON COMMUNITY STRUCTURE AND ITS ENVIRONMENTAL RESPONSE IN THE THREE GORGES RESERVOIR (CHINA) IN 2014
}

\author{
LIU, M.-Q. ${ }^{1,2}$ - LIU, Z.-X. ${ }^{1}-$ HoU, Y.-Y. ${ }^{1}-$ LIU, K.-S. ${ }^{1}-$ LIU, X.-L. ${ }^{1}-$ CHEN, Q. ${ }^{1}-$ LIU, X.-X. ${ }^{1}-$ \\ LI, Y.-T. ${ }^{1}-\mathrm{HOU}, \mathrm{J}^{--J} .^{1 *}-\mathrm{BI}$, Y.-H. ${ }^{*}$ \\ ${ }^{1}$ Hubei Key Laboratory of Edible Wild Plants Conservation and Utilization, Hubei Normal \\ University, Huangshi 435002, China \\ ${ }^{2}$ Zhejiang Normal University, College of Chemistry and Life Sciences, Jinhua 321004, China \\ ${ }^{3}$ State Key Laboratory of Freshwater Ecology and Biotechnology, Institute of Hydrobiology, the \\ Chinese Academy of Sciences, Wuhan 430072, China \\ *Corresponding authors \\ e-mail/phone: jjhou@hbnu.edu.cn/+86-71-4651-1613 (J.-J. Hou); biyh@ihb.ac.cn/+86-27- \\ 6878-0016 (Y.-H. Bi)
}

(Received 24 $4^{\text {th }}$ Apr 2019; accepted $12^{\text {th }}$ Jul 2019)

\begin{abstract}
To characterize the ultraphytoplankton community structure and understand its succession and its relationship with environmental factors, High Performance Liquid Chromatography (HPLCCHEMTAX) was used to analyze the photosynthetic pigment concentration and the algae composition. Algal phyla composition and their abundance were determined based on the presence of pigments, and environmental parameters were synchronously tested in the Three Gorges Reservoir in China. Highperformance liquid chromatography (HPLC) analysis showed that there were eight characteristic photosynthetic pigments in the Three Gorges reservoir area: alloxanthin, chlorophyll b, chlorophyll a, fucoxanthin, lutein, neoxanthin, violaxanthin, and zeaxanthin. Among them, fucoxanthin, allophycocyanin, zeaxanthin, and chlorophyll $\mathrm{b}$ were the most important photosynthetic pigments in the Three Gorges reservoir area. There were significant differences in the time scale of the eight photosynthetic pigments $(P<0.05)$, but no significant difference in the seven phyla $(P>0.05)$. The calculation of the matrix factorization program chemical taxonomy (CHEMTAX) showed that the ultraphytoplankton community was composed of 7 phyla: Euglenophytes, Chrysophytes, Cyanophytes, Cryptophytes, Chlorophytes, Diatoms, and Dinoflagellates. Redundancy analysis (RDA) revealed that the key environmental factors that affected the structure of the ultraphytoplankton community were light intensity, total phosphorus, and water temperature. The results provided a basis and data support for the biodiversity of phytoplankton in the Three Gorges Reservoir and its relationship with environmental factors and environmental monitoring.
\end{abstract}

Keywords: photosynthetic pigment, HPLC, CHEMTAX, total biomass, environmental factor

\section{Introduction}

Ultraphytoplankton include all picoplankton $(0.2 \sim 2 \mu \mathrm{m})$ and $2 \sim 5 \mu \mathrm{m}$ microplankton $(<20 \mu \mathrm{m})$ (Ning, 1997). Ultraphytoplankton are light-dependent selfsustaining creatures that consist of prokaryotes and eukaryotes (Sieburth et al., 1978). Ultraphytoplankton are an important source of gross primary productivity and are distributed around the world, some in extreme conditions, such as high temperatures in tropical and subtropical regions, the frigid Antarctic, as well as oceans and lakes under a variety of nutrient conditions. Currently, the prokaryotes cyanobacteria, such as Synechococcus and Prochlorococcus, are a familiar subject in marine 
ultraphytoplankton research (Coclet et al., 2017; Chen et al., 2011; Glove et al., 1988), while there are very few studies in fresh water.

As the world's largest deep-water reservoir, the Three Gorges Reservoir of China has huge economic benefits in terms of flood control, shipping and power generation. However, after the damming of the Yangtze River, it underwent tremendous changes in the hydrological situation and water environment (Huang and $\mathrm{Li}, 2006$ ). The hydrodynamic characteristics of some reservoirs and tributaries have changed significantly. The velocity of the water flow has been markedly slowed, and the flow rate of many tributaries (A river that flows into another river (or other body of water) rather than directly into the sea.) is less than $0.05 \mathrm{~m} \cdot \mathrm{s}^{-1}$, which is due to the influence of reservoir hydrodynamics and the backwater effect (Deng and Gong, 2007; Li et al., 2007). The decrease in the flow rate causes the vertical flow of the target area to decrease and the residence time of the water to increase significantly, resulting in the sedimentation of suspended matter in the water (Zheng et al., 2008). Under the appropriate temperature, wind speed, light, and biological factors, such as the impact of phytoplankton, the changing conditions will cause the algae to undergo explosive growth into a "bloom" (Kong and Gao, 2005) and thus have a negative impact on the reservoir ecosystem.

Regarding phytoplankton in the Three Gorges Reservoir, there are many reports on microplankton and picoplankton (Pan et al., 2016; Liu et al.,2012; Zhou et al., 2009), but research data for ultraphytoplankton is lacking. The key and prerequisite for studying ultraphytoplankton are to classify them.

The classical phytoplankton taxonomy mainly uses microscopic observation and flow cytometry. The use of electron microscopy and optical microscopy for traditional morphological observation is the basis on which we can also use the cell count plate for sample identification of the count (Wasilowska et al., 2015). This traditional method is indispensable in phytoplankton classification and identification, but it is extremely difficult to classify phytoplankton with minimal particle sizes (e.g., ultraphytoplankton). Although flow cytometry techniques can accurately and efficiently count microscopic phytoplankton that are difficult to observe, it is a challenge to distinguish the phyla of phytoplankton in the sample (Bonato et al., 2016). On the other hand, if there are aggregates and debris in the sample cells, the resulting fluorescence interference will directly affect the test results. Compared with these methods, chemical classification has the advantages of being fast and accurate, with a high-throughput (Li et al., 2013).

Chlorophyll a plays an important role in photosynthesis and is considered a biomarker of phytoplankton in the world (Alvarez-Fernandez and Riegman, 2014). Scientists (Jeffrey, 1974; Hallegraeff, 1981) have recognized the taxonomic significance of different photosynthetic pigments and their composition in phytoplankton. The distribution of different pigments in algae is distinct and exists only in phytoplankton communities (Wright et al., 1991). Therefore, it is feasible and scientific to determine the characteristic photosynthetic pigments of phytoplankton in order to establish phytoplankton groups. Chromatographic techniques, especially reverse-phase high-performance liquid chromatography (RP-HPLC) technology, can be used in analyzing algae pigment content and composition changes, combined with the characteristic photosynthetic pigment and chlorophyll a initial ratio data, through the matrix factorization program CHEMTAX. In addition, the abundance and composition of the phytoplankton population can also be determined using 
CHEMTAX. The chemical classifications based on HPLC-CHEMTAX pigment analysis can accurately analyze the phytoplankton community structure and abundance composition, and it is not limited by the phytoplankton grain size. The study of biomass change, taxa composition, and community structure succession of the ultraphytoplankton are significant in modern science. Although this method has been widely used in the study of marine phytoplankton composition and abundance (Madhu et al., 2014; Agirbas et al., 2015), it has not been frequently used in fresh water. To explore the dynamics of the ultraphytoplankton community structure in the Three Gorges Reservoir, our group applied this technique, which can quickly and accurately describe the community structure of the ultraphytoplankton ( $\mathrm{Li}, 2014$; Liu et al., 2017).

This study used HPLC-CHEMTAX technology aimed at specific pigments of the ultraphytoplankton to analyze the succession of the ultraphytoplankton community structure and its response to environmental factors in the Three Gorges Reservoir. Specifically, the main objectives of this study were as follows: (i) to discover the spatial and temporal distribution of the total biomass of the ultraphytoplankton in the Three Gorges Reservoir; (ii) to determine the concentration of photosynthetic pigments using HPLC to discover the algae community composition and to determine the dominant algal populations in different spatiotemporal and spatial conditions; and (iii) to illustrate the relationship between community structure and environmental factors of ultraphytoplankton by redundancy analysis. Therefore, this study provided Three Gorges Reservoir plant biodiversity research and eco-environmental management with baseline and basic data.

\section{Methods}

\section{Sampling point setting}

The Three Gorges Reservoir is an artificial channel lake formed after the completion of the Three Gorges Hydropower Station, which is located at east longitude $107^{\circ} 20^{\prime}-111^{\circ} 02^{\prime}$, north latitude $30^{\circ} 31^{\prime}-30^{\circ} 20^{\prime}$, through the provinces of Chongqing and Hubei in China. It covers 19 counties and cities in the Chongqing and Hubei Provinces, with a total area of $54,000 \mathrm{~km}^{2}$. Based on the topographic features of the Three Gorges Reservoir, the degree of eutrophication, the status of the bloom, the level of nutrients, the hydrodynamic characteristics, and related literature research, the sampling points were determined as follows: we had a total of 26 sample sites, including 9 major tributaries of Chongqing, namely, the Tangxihe (TXH), Pengxihe (Xiaojiang, XJ), and Modaoxi (MDX) in Yunyang County, the Zhuxihe ( $\mathrm{ZXH}$ ), Caotanghe $(\mathrm{CTH})$, and Meixihe $(\mathrm{MXH})$ in Fengjie County, the Quma Town of Xiaojiang (QM) and KaiCoungty of Xiaojiang (KX) in Kai County, and Daninghe $(\mathrm{DNH})$ in Wushan County and 6 tributaries in the Hubei reservoir area, including Shennong Creek (SN01-SN03) and Mianzhuxia (MZX) in Badong county, Xiangxihe (XX01-XX08) in Xiangxi County, and Yuanshuihe (YSH), Qingganhe (QGH), and Tong zhuanghe $(\mathrm{TZH})$ in Zigui County, as well as the main stream of the Yangtze River (CJ01, CJ05). See Figure 1 for details. 


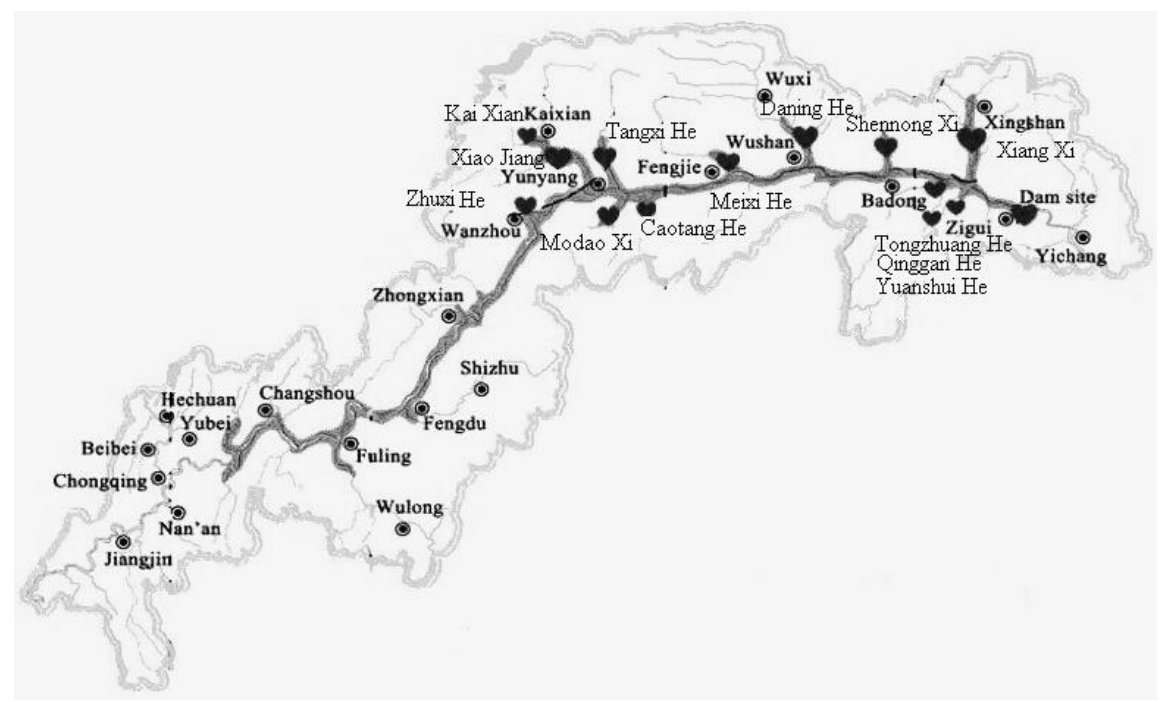

Figure 1. Distribution of sampling sites in the Three Gorges Reservoir during 2014

\section{Monitoring frequency and sampling method}

We chose two-month sampling, and the sampling time was from February to December of 2014. A total of 154 samples were collected from 26 stations each time (of which the stations XX08 in June and August were in dry season). Sampling on the 15th17 th of each month, and there were three replicates per site. A $1.5-\mathrm{L}$ water sample was collected using a 5-L organic glass water sampler and was placed in a plastic bottle. Black plastic bags were then used to wrap the plastic bottles, and the samples were returned to the experimental station after the start of filtration. The water samples were passed through a $10-\mu \mathrm{m}$ sieve, a 5- $\mu \mathrm{m}$ Millipore nuclear membrane, and a $0.7-\mu \mathrm{m} \mathrm{GF} / \mathrm{F}$ (Whatman), successively. The sample films containing the ultraphytoplankton were prepared, wrapped with tin foil to avoid light exposure, and kept in liquid nitrogen.

\section{Determination of characteristic photosynthetic pigment contents by HPLC}

The sample processing method was as follows: the sample film was cut into $5 \mathrm{~mm} \times$ $1 \mathrm{~cm}$ of debris and placed in a 2-mL Eppendorf tube. After adding $1 \mathrm{~mL} \mathrm{~N}, \mathrm{~N}$ dimethylformamide (DMF) for pigment extraction and mixing, the extract was placed in the refrigerator at $-20^{\circ} \mathrm{C}$ for $40 \mathrm{~min}$. The sample was then centrifuged for $5 \mathrm{~min}$ at a rotational speed of $4000 \mathrm{r} / \mathrm{min}$, filtered with a $0.22-\mathrm{M}$ filter membrane, and mixed with $1 \mathrm{M}$ ammonium acetate solution with a volume of 1:1 for Infinity 1260 Series HPLC (Agilent, USA) analysis. The chromatographic separation was carried out on a C8 column (Zorbax Eclipse xdb-C8 $4.6 \times 150 \mathrm{~m}, 3.5 \mathrm{um}$, Agilent, USA) and a 36-min elution procedure.

According to a method in the literature (Li et al., 2015), the external standard method was used to carry out the quantitative analysis, the gradient elution program and the quantitative calculation formula reference (Hu et al., 2011). The identified photosynthetic pigments are as follows: alloxanthin (Allo), chlorophyll $b$ (Chl-b), chlorophyll $a$ (Chl-a), fucoxanthin (Fuco), lutein (Lute), neoxanthin (Neox), peridinin (Peri), violaxanthin (Viol), and zeaxanthin (Zeax). Combined with the single factor analysis of variance function in the statistical analysis software SPSS 17.0, the significance was analyzed. 


\section{The community structure of the ultraphytoplankton}

The data obtained in the field on the initial ratios of photosynthetic pigments and their concentrations were entered in the matrix of the CHEMTAX software to calculate the characteristics of the ultraphytoplankton community structure in the Three Gorges Reservoir. ANOVA was performed using SPSS 17.0 (Statistical Product and Service Solutions) software, and the significance of functional analysis was analyzed.

\section{Analysis of environmental factors}

The environmental and physical indicators of the study included 10 physical and chemical indicators for outdoor measurement, consisting of $\mathrm{pH}$, water temperature (WT), air temperature (AT), transparency (SD), conductivity (SPC), Illumination-water (IllumW), Illumination-air (Illum-A), Turbidity (Turbidity), and dissolved oxygen (DO), and 7 indoor measurements of water chemistry, consisting of total phosphorus (TP), total nitrogen $(\mathrm{TN})$, ammonium salt $\left(\mathrm{N}-\mathrm{NH}_{4}{ }^{+}\right)$, phosphate $\left(\mathrm{P}-\mathrm{PO}_{4}{ }^{3-}\right)$, nitrate $\left(\mathrm{N}-\mathrm{NO}_{3}{ }^{-}\right)$, and chemical oxygen demand (COD). The physical and chemical indicators for outdoor measurement were mainly measured by YSI (dissolved oxygen meter), transparency disk, and photometer. The analysis and test methods of the indoor measurements of water chemistry mainly adhered to the "Surface Water Environmental Quality Standard - GB3838-2002".

\section{Redundancy analysis of the relationship between environmental factors and community structure}

If the results of the Monte Carlo test and environmental variables screened showed significant difference $(P<0.05)$, the relationship between environmental factors and the community structure of the ultraphytoplankton could be explained by the RDA analysis module. Ordination plots were made by CANOCO for Windows 4.5 software.

\section{Results}

\section{Total biomass of the ultraphytoplankton}

It is universally acknowledged that chlorophyll a content indicates the total biomass of the ultraphytoplankton. Therefore, the temporal and spatial distribution of the total biomass of the ultraphytoplankton was identified by analyzing the changes in the content of Chl- $a$ at 26 sampling sites (Fig. 2).

The concentration range of Chl-a in the Three Gorges Reservoir area was 6.39$18,781.96 \mu \mathrm{g} / \mathrm{m}^{3}$, In April, June, and August, the total biomass of the ultraphytoplankton was higher, with the highest value being 18,781.96 $\mu \mathrm{g} / \mathrm{m}^{3}$ (August; ZXH). In October and December, the total biomass was lower, and the lowest value appeared at the ZXH station in October. The Chl-a concentration of the ultraphytoplankton ranged from 6.39 to $12,704.99 \mu \mathrm{g} / \mathrm{m}^{3}$ in the Hubei reservoir area. In April and June, the concentration of Chl-a was the highest, with the highest value at the XX07 station in April. The concentration of Chl-a was lower in October and December, with the lowest value at the ZXH station in October. The concentration range of Chl-a in the Chongqing reservoir area was 28.97$18,781.96 \mu \mathrm{g} / \mathrm{m}^{3}$. The Chl-a concentration was higher in August, indicating that the total biomass was the largest, with the highest value at the ZXH site. Lower values were found in December, with the lowest value at the MXH site. Overall, the total biomass of the 
ultraphytoplankton in the Hubei reservoir area was slightly higher than that in Chongqing reservoir area.

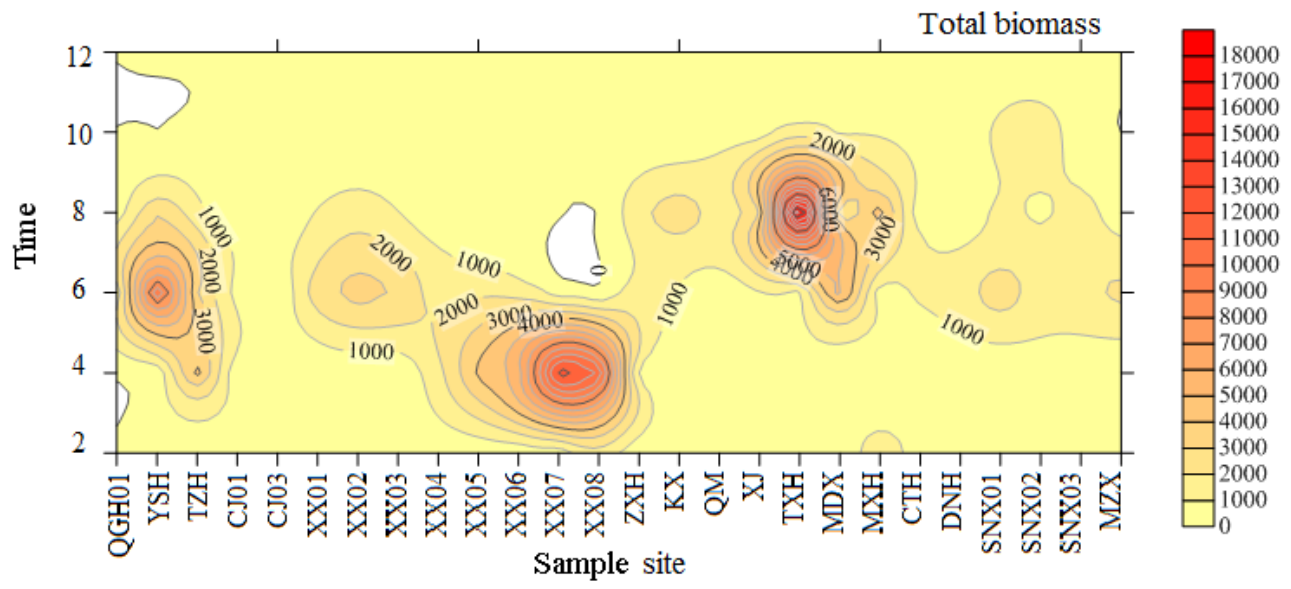

Figure 2. Temporal and spatial changes of the total biomass

By using the method of one-way ANOVA, the spatial and temporal differences are analyzed. The results showed that there was significant difference between June and December $(P<0.05)$, and there was no significant difference between the other months $(P>0.05)$. There was also no significant difference in total biomass with space $(P>0.05)$. Therefore, the total biomass is greatly influenced by time of year.

\section{Types of photosynthetic pigments of the ultraphytoplankton}

Based on HPLC technology, the photosynthetic pigment composition and content of the ultraphytoplankton in 26 stations in the main stream and tributaries of the Three Gorges reservoir area in 2014 were monitored, and their temporal, spatial, and distribution patterns were analyzed. The results showed that 8 special pigments of the ultraphytoplankton were detected in the Three Gorges Reservoir, including Fuco, Viol, Allo, Lute, Neox, Zeax, Chl-b and Chl-a. Among the target characteristic photosynthetic pigments, Allo, Zeax, Fuco, and Chl-b were the main photosynthetic pigments found in the ultraphytoplankton in the waters of the reservoir area. The total biomass of the ultraphytoplankton, indicated by the content of the Chl-a, has been discussed in the total biomass. The temporal and spatial distribution of the other seven photosynthetic pigments is as follows.

The temporal and spatial distribution of fucoxanthin is shown in Figure 3A. In April, the concentration of Fuco was higher, with an average of $534.07 \mu \mathrm{g} / \mathrm{m}^{3}$. The highest concentration was $3,621.85 \mu \mathrm{g} / \mathrm{m}^{3}$ at the XX08 site. In October and December, the concentration of Fuco was lower, with an average concentration of $13.69 \mu \mathrm{g} / \mathrm{m}^{3}$, and the lowest concentration was $3.39 \mu \mathrm{g} / \mathrm{m}^{3}$ at the QGH site. The Fuco concentration in the Hubei reservoir area was higher than that in the Chongqing reservoir area.

The temporal and spatial distribution of neoxanthin is shown in Figure 3B. In June, the concentration of Neox was higher, with an average of $25.38 \mu \mathrm{g} / \mathrm{m}^{3}$ and a maximum of $158.63 \mu \mathrm{g} / \mathrm{m}^{3}$ at ZXH. In December, the concentration of Neox was lower, with an average of $0.25 \mu \mathrm{g} / \mathrm{m}^{3}$ and a minimum of $0.12 \mathrm{mg} / \mathrm{m}^{3}$ at CJ03, while the Neox concentration in the Chongqing reservoir area was slightly higher than that of the Hubei reservoir area. 


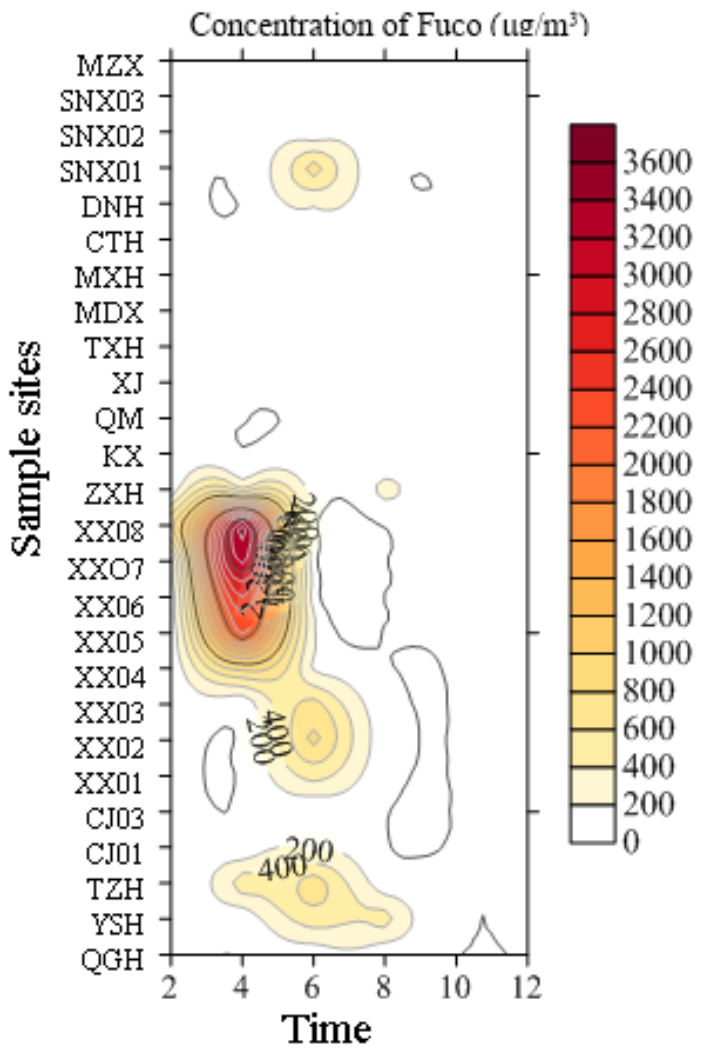

A. Fuco

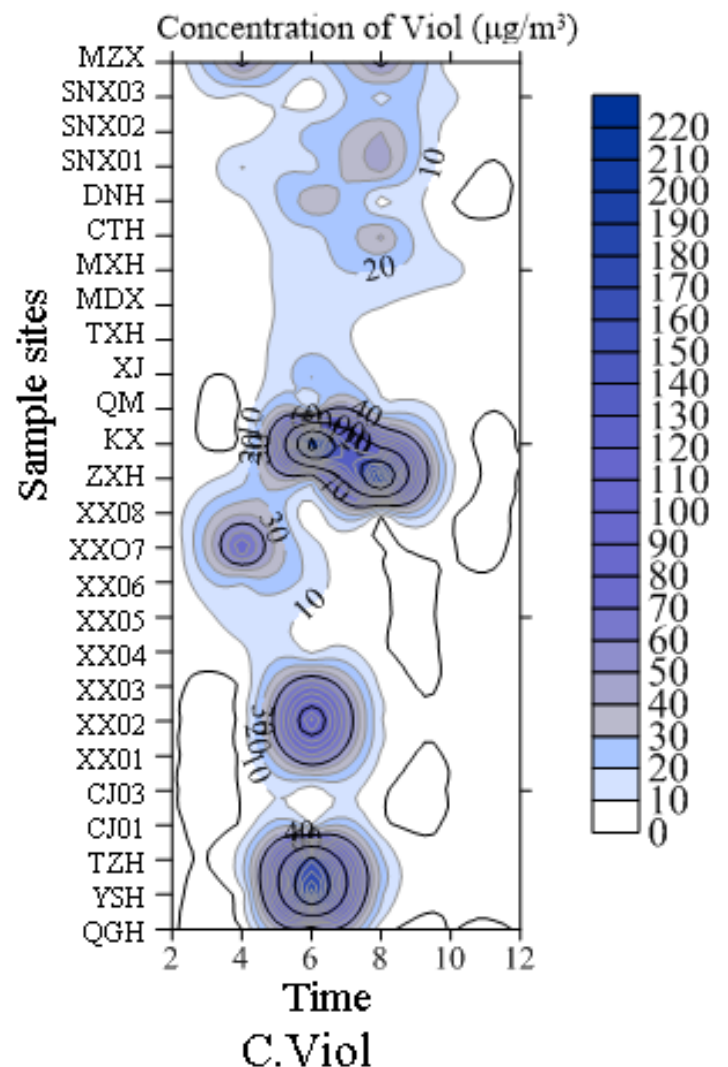

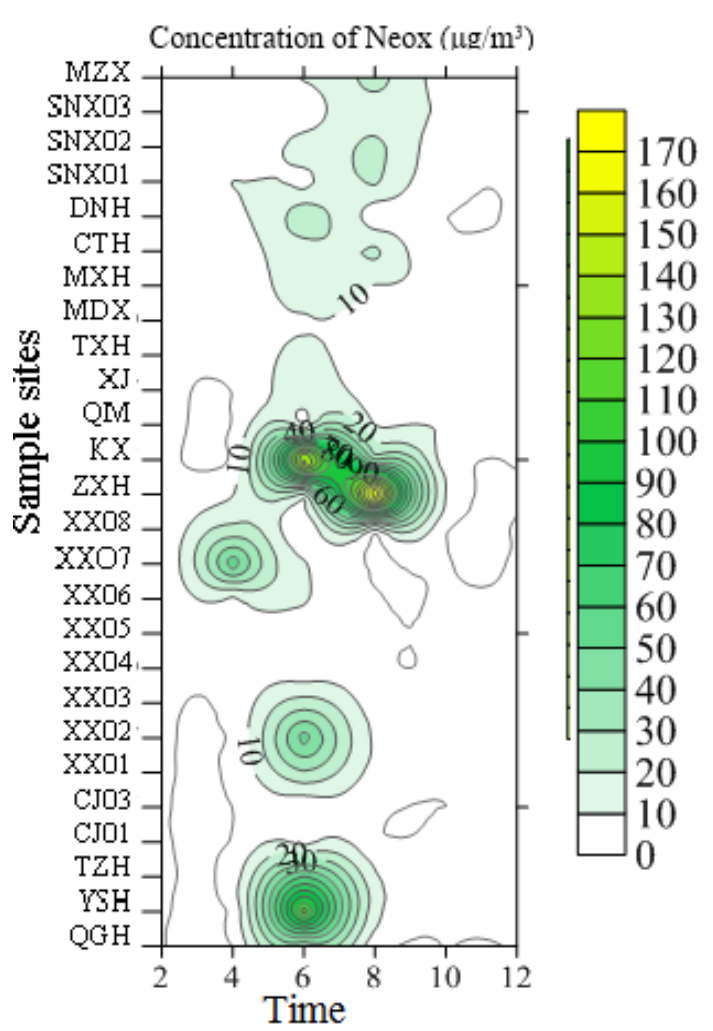

B. Neox

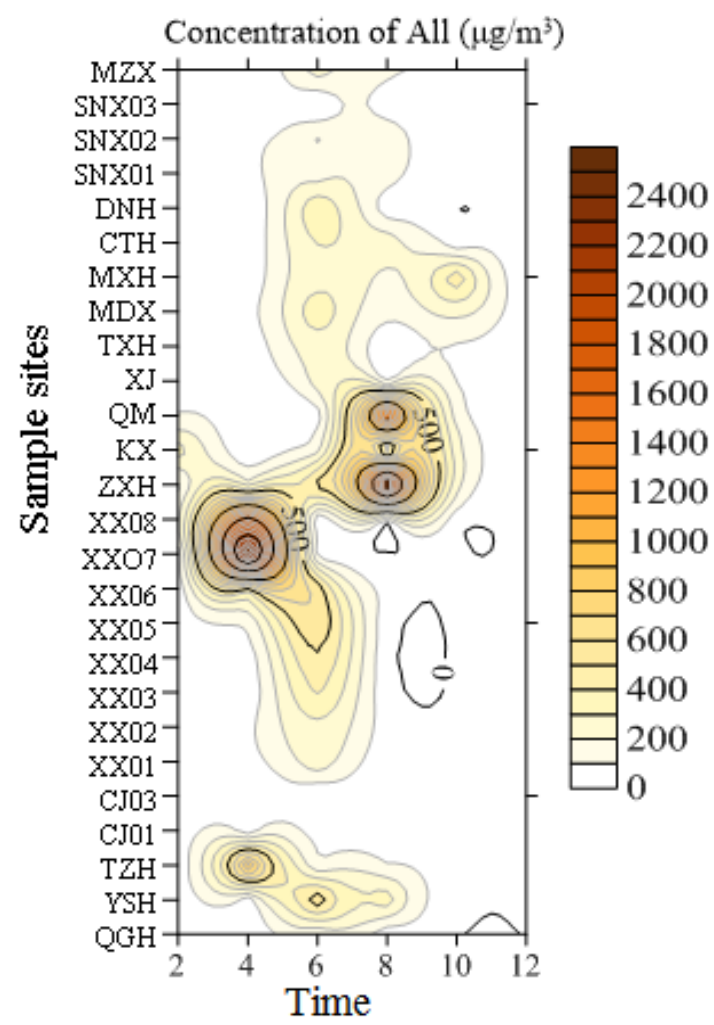

D. Allo 


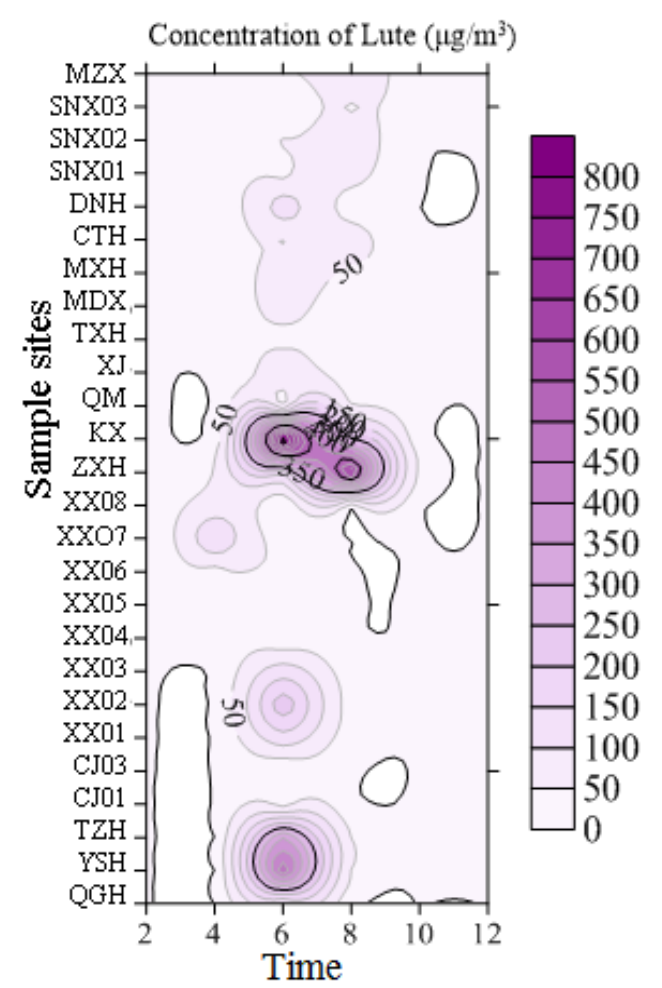

E. Lute

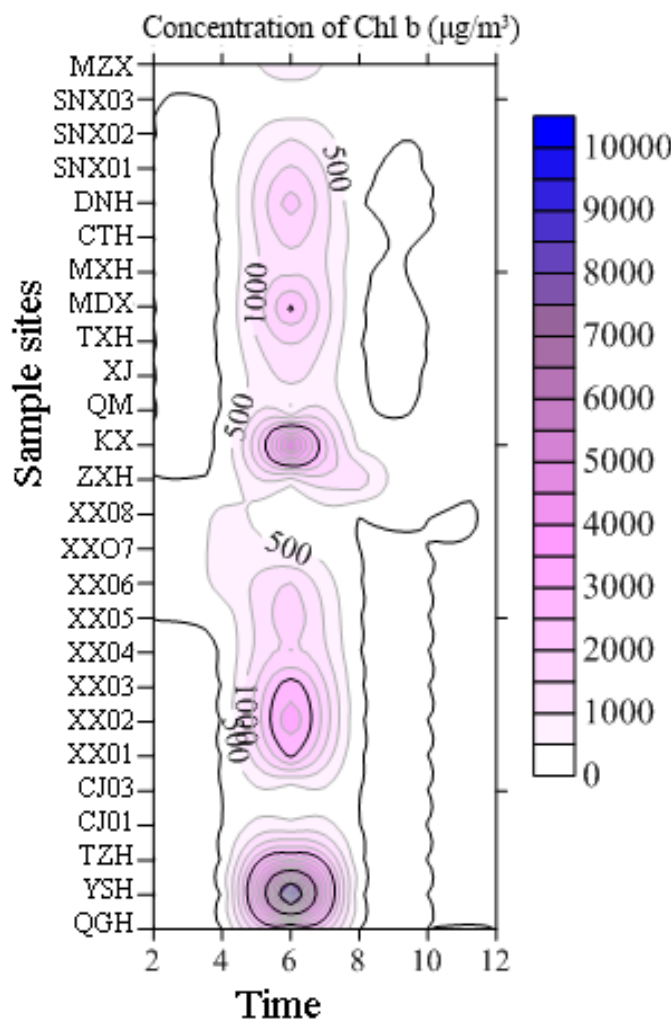

G. Chl b

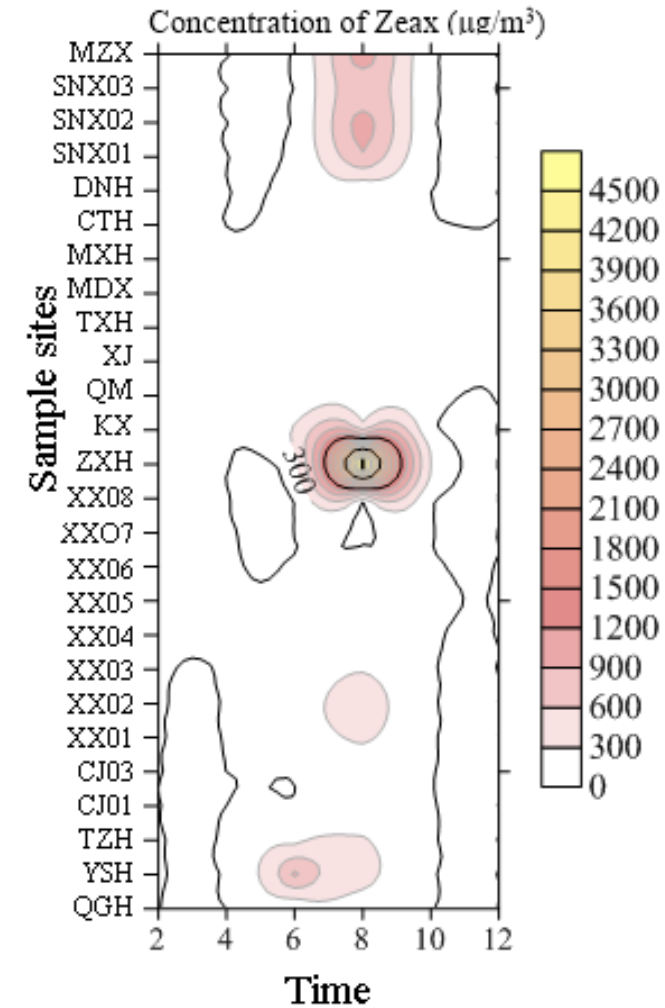

F. Zeax

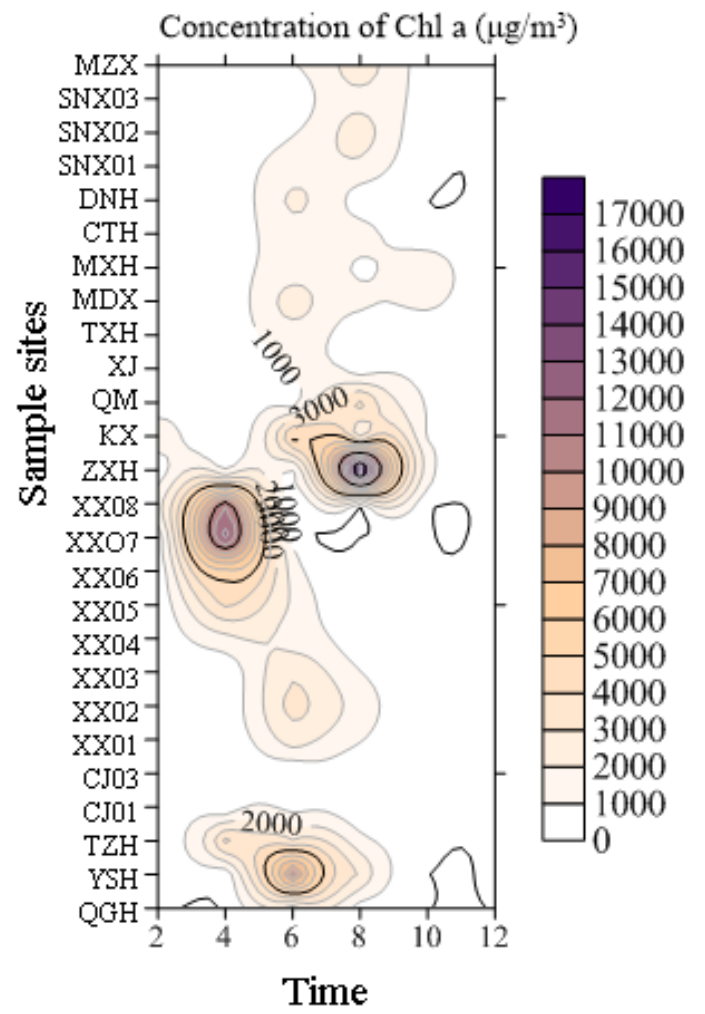

H. Chl a

Figure 3. Biomark photosynthetic pigments temporal and spatial distribution 
The spatial and temporal distribution of violaxanthin is shown in Figure $3 C$. In June, the concentration of Viol was higher, with an average of $45.8 \mu \mathrm{g} / \mathrm{m}^{3}$, and the highest concentration was $198.32 \mu \mathrm{g} / \mathrm{m}^{3}$ at YSH. The concentration of Viol in December was lower, with an average of $0.41 \mu \mathrm{g} / \mathrm{m}^{3}$, and the lowest value was $0.13 \mu \mathrm{g} / \mathrm{m}^{3}$ at CJ01. Its distribution in space showed an obvious difference, while the Viol concentration in the Hubei reservoir area was higher overall than that of the Chongqing reservoir area.

The temporal and spatial distribution of alloxanthin is shown in Figure 3D. In April (average: $254.79 \mu \mathrm{g} / \mathrm{m}^{3}$ ) and June (average: $259.64 \mu \mathrm{g} / \mathrm{m}^{3}$ ), the Allo concentration was higher, with a maximum of 2,295.64 $\mu \mathrm{g} / \mathrm{m}^{3}$ (April; XX07). In December, the Allo concentration was lower, with an average of $10.44 \mu \mathrm{g} / \mathrm{m}^{3}$ and a minimum of $0.75 \mu \mathrm{g} / \mathrm{m}^{3}$ at the $\mathrm{CJ} 03$ site. The concentration of the Chongqing reservoir area was higher than that of the Hubei reservoir area.

The temporal and spatial distribution of lutein is shown in Figure $3 E$. In June, the Lute concentration was higher, with an average of $122.86 \mu \mathrm{g} / \mathrm{m}^{3}$, and the highest value appeared at the KX site $\left(851.37 \mu \mathrm{g} / \mathrm{m}^{3}\right)$. In December, the concentration of Lute was lower; its average was $1.34 \mu \mathrm{g} / \mathrm{m}^{3}$, and the minimum value was $0.46 \mu \mathrm{g} / \mathrm{m}^{3}$ at the CJ03 site. The concentration of Lute in the Chongqing reservoir area was higher than that in the Hubei reservoir area.

The temporal and spatial distribution of zeaxanthin is shown in Figure $3 F$. In August, the Zeax concentration was higher, with an average of $482.80 \mu \mathrm{g} / \mathrm{m}^{3}$, and the highest value appeared at the $\mathrm{ZXH}$ site $\left(5,214.18 \mu \mathrm{g} / \mathrm{m}^{3}\right)$. In December, the concentration of Zeax was lower; its average value was $1.98 \mu \mathrm{g} / \mathrm{m}^{3}$, and the minimum value of $0.42 \mu \mathrm{g} / \mathrm{m}^{3}$ was at the CJ03 site. The concentration of Zeax in the Chongqing reservoir area was significantly higher than that in the Hubei reservoir area.

The temporal and spatial distribution of chlorophyll b was shown in Figure $3 G$. In June, the Chl- $b$ had the highest concentration, and its average was $1,927.22 \mu \mathrm{g} / \mathrm{m}^{3}$. In December, the Chl-b had the lowest concentration, with an average of $2.05 \mu \mathrm{g} / \mathrm{m}^{3}$. In February, the concentration of the Chl-b at sites XX08 and KX was $0 \mu \mathrm{g} / \mathrm{m}^{3}$, and the concentration of the Chl-b in the Hubei reservoir area was higher than that in the Chongqing reservoir area.

Except for the Chl- $a$, the other seven characteristic photosynthetic pigments were analysed by a variance homogeneity test and single factor analysis of variance. The results showed that the contents of the photosynthetic pigments including Fuco, Neox, Viol, Allo, Zeax, Lute and Chl-b were significantly different $(P<0.05)$ with time, but there was no significant difference $(P>0.05)$ in the spatial variation.

\section{The community structure rules of the ultraphytoplankton}

The community structure rules of the ultraphytoplankton were shown in Figure 4, and the significant taxa of the ultraphytoplankton were Diatoms, Euglenophytes, Cryptophytes and Chrysophytes in different samples for the whole year. In February (Fig. 4A), the dominant populations were Diatoms, Cryptophytes and Euglenophytes. The sharp increase in the number of the Diatom phyla appeared at the XX08, TXH, $\mathrm{MXH}$, and SNX01 sites; the sharp increase in the number of the Cryptophyta phyla appeared at the TZH, CJ01, XX05, KX, MDX and DNH sites. The rest of the site group structures showed more uniform changes. In April (Fig. 4B), Cryptophytes and Diatoms were the principal phyla from sites QGH to XX04, and the Diatoms were the dominant population at sites XX05 and XX06; the major phyla were replaced by Cryptophytes from sites XX07 to MZX. In June (Fig. 4C), the primary phyla was Cyanobacteria, 
Euglenophytes and Diatoms, and the rest samples did not have excessive changes of community structure. In August (Fig. 4D), the number of the Euglenophytes was higher than Cryptophytes. The community structure of each samples' change was obvious, and the major phyla were changed from Cryptophytes to Euglenophytes. Among them, the proportion of the Diatoms at the YSH site increased sharply, and the proportion of the Cryptophytes at the QM site increased sharply, while the proportion of the Diatoms at the MZX site decreased drastically. In October (Fig. 4E), the Euglenophytes accounted for $85 \%$ of the taxa at all samples except YSH. In December (Fig. 4F), Euglenophytes was the superior taxa, and the rest of the algae abundance was equal. However, Cycanobacteria were the significant taxa at $\mathrm{ZXH}$, and Chrysophytes were the dominant taxa at MXH.
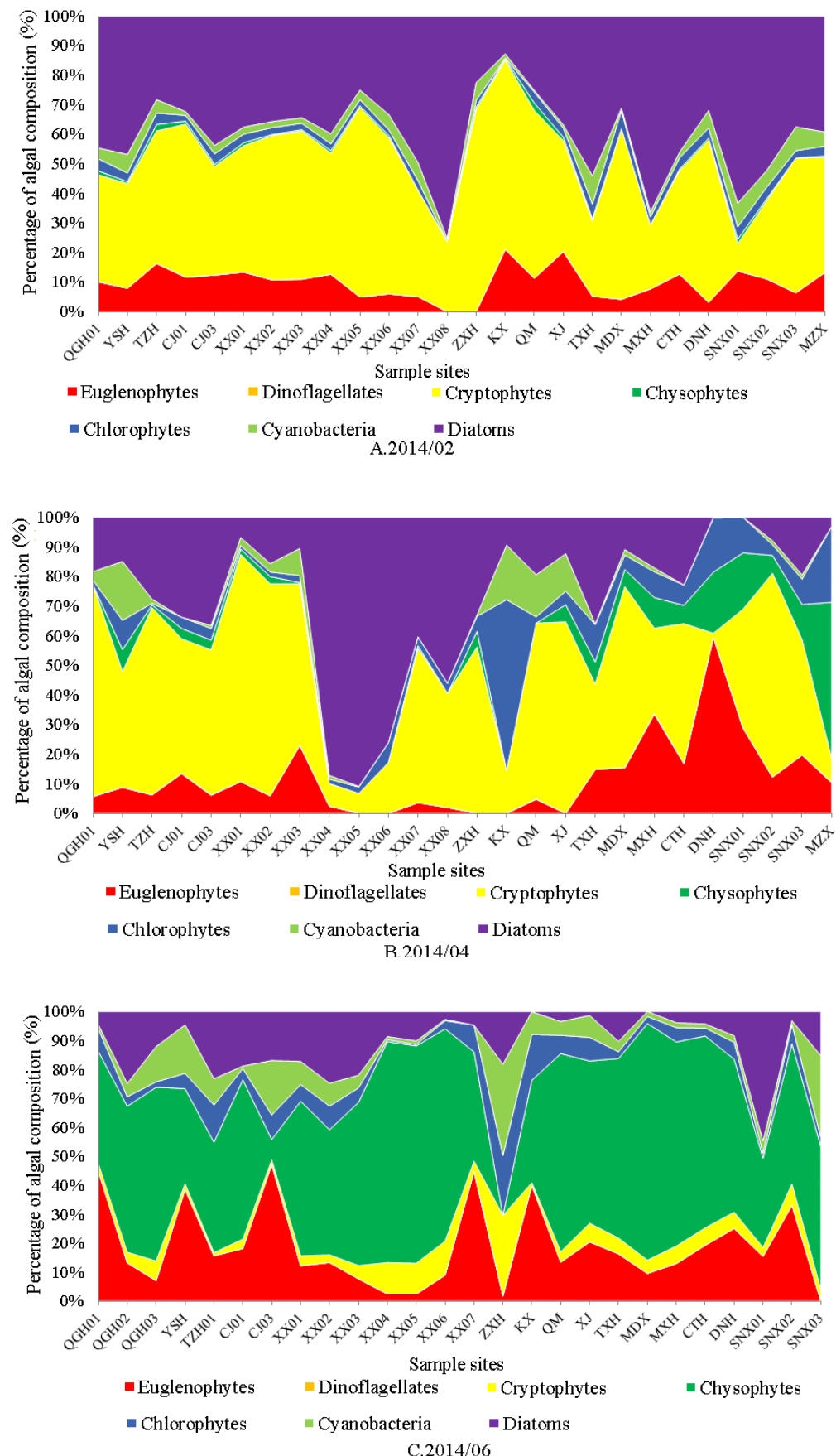

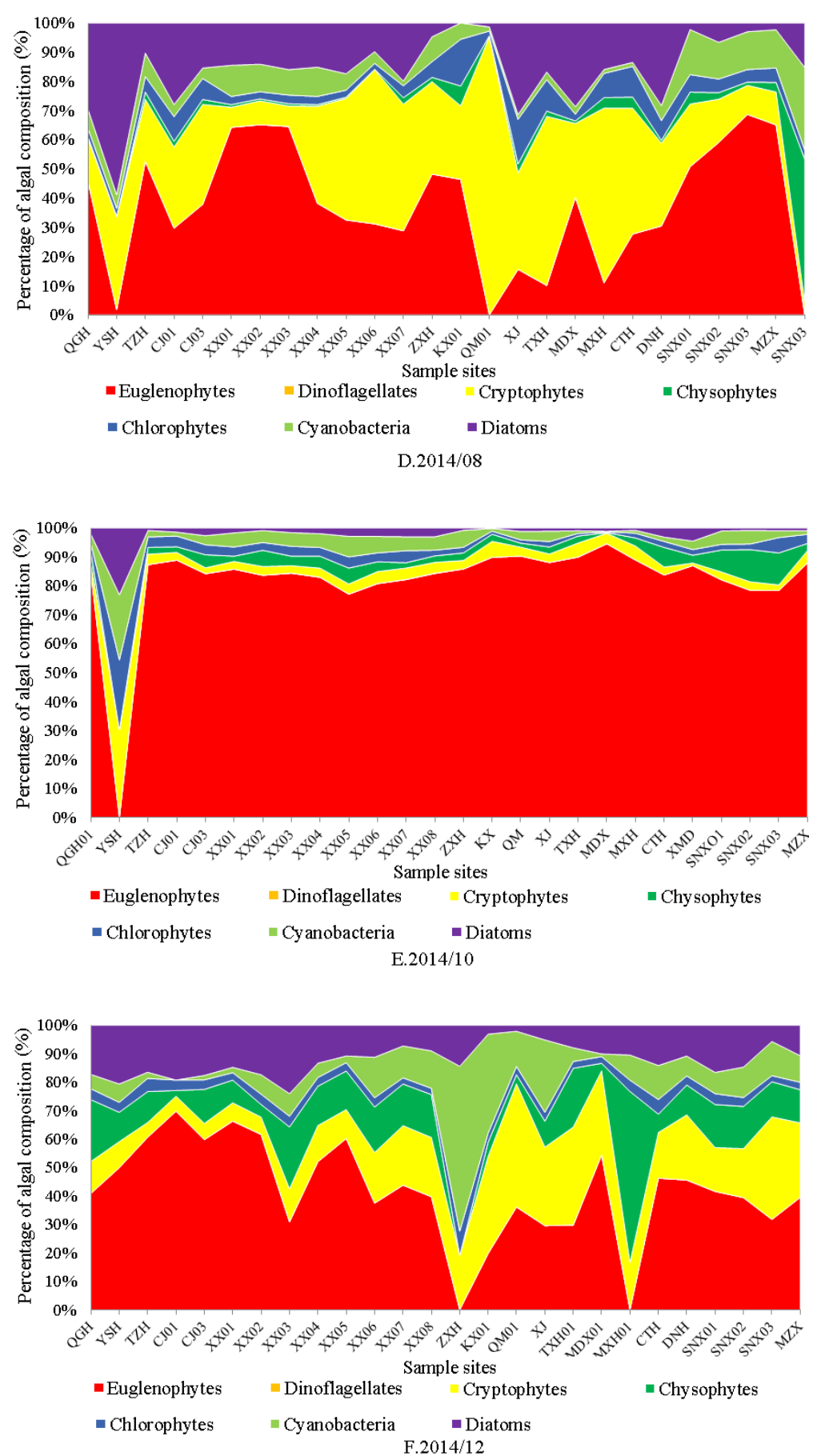

Figure 4. Temporal and spatial variations of the ultraphytoplankton community structure

The relationships of time and station were analysed by using the single factor variance of the ultraphytoplankton community structure of the Three Gorges Reservoir. The results showed that the community structure changes over time had significant differences $(P<0.05)$, and there was no significant difference in space $(P>0.05)$. Therefore, community structure was more influenced by the time. The investigation of time change was essential to the change of community structure. 


\section{Environmental responses of ultraphytoplankton}

The relationships between the ultraphytoplankton community structure and environmental factors were investigated in the Three Gorges Project. The relevance was significantly different in the ultraphytoplankton community structure and environmental factors in February, April, June, and August $(P<0.05)$ rather than October $(P>0.05)$.

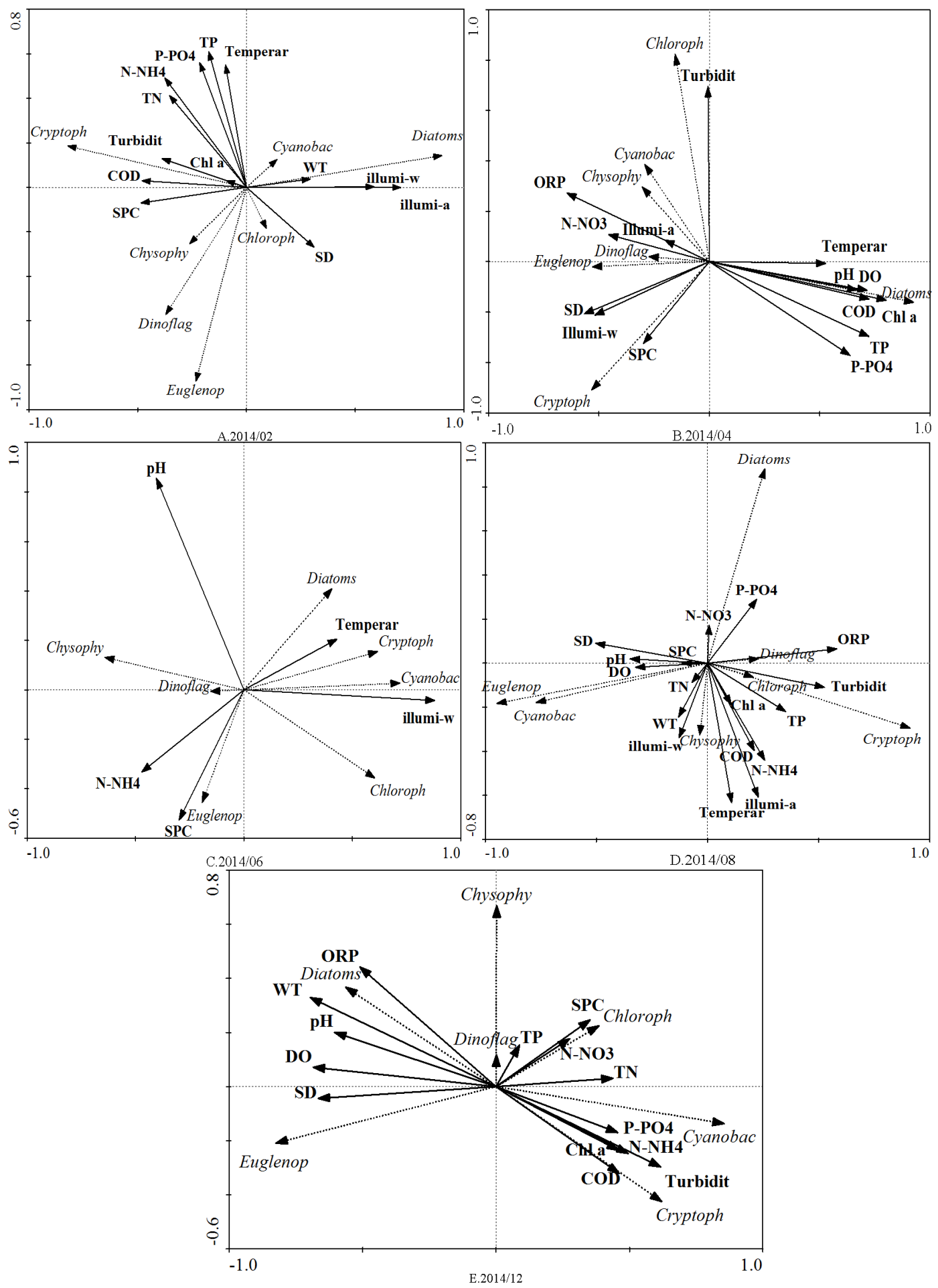

Figure 5. RDA analysis of the relationship between environmental factors and the ultraphytoplankton phyla assemblages obtained by RDA 
In February (Fig. 5A), the superior taxa of algae were Diatoms and Cryptophytes. Relevance analysis between the ultraphytoplankton community structure and environmental factors indicated that WT and illumination were the most important limiting environmental factor. The environmental factors had a significant negative correlation with Cryptophytes, and algal abundance had a significant positive correlation with Diatoms. In April (Fig. 5B), the principal phyla of algae were Diatoms and Cryptophytes. TP was the all-important limiting environmental factor. In June (Fig. 5C), the primary phyla of algae were Cyanobacteria and Chysophytes, and relevance analysis between the ultraphytoplankton community structure and environmental factors indicated that $\mathrm{pH}$ and Iillumi-w were the most vital limiting environmental factor. In August (Fig 5D), the superior taxa of algae were the Euglenophytes and Cryptophytes. Relevance analysis between the ultraphytoplankton community structure and environmental factors indicated that DO and SPC were the most essential limiting environmental factor. In October, pre-screening and Monte Carlo tests found that it was unsuited to RDA analysis $(P>0.5)$. In December (Fig. 5E), the primary phyla of algae was Euglenophytes. RDA analysis showed that SD and DO were the most considerable environmental factor.

\section{Discussion}

Studies have shown that there is a positive correlation between the biomass of phytoplankton and the content of the Chl-a (Alvarez-Fernandez and Riegman, 2014). In this study, the Chl- $a$ of the ultraphytoplankton was used to represent the biomass, and the Chl- $a$ concentration of the ultraphytoplankton $(<5 \mu \mathrm{m})$ ranged from $6.39 \mu \mathrm{g} / \mathrm{m}^{3}$ to $18,781.96 \mu \mathrm{g} / \mathrm{m}^{3}$. It had also been found in earlier research (Silva et al., 2009) that the contribution rate of the ultraphytoplankton of total phytoplankton was 0.2-99.7\%. Instead, the contribution rate of the ultraphytoplankton in fresh water was in the low. In keeping with the distribution of the Chl- $a$ in the Three Gorges, the biomass of the ultraphytoplankton in April, June, and August were higher than other months, and it reached the maximum in August. Therefore, August probably developed into the outbreak period of the ultraphytoplankton. Liu et al. (2017) have found that the total chlorophyll a content of ultraphytoplankton was higher in the Xiangxi River Basin of the Three Gorges Reservoir in April and August, which is consistent with the results of this study. The research, which was put forth by Xiang Yingchun in 2014, had shown that, during 2011 and 2014 at the ZXH site, every month showed eutrophication. In conclusion, monitoring the change of the ultraphytoplankton biomass could be used to assess environmental status.

Studies (Wright, 1991; Li et al., 2013) have shown that the characteristic pigments only presented in a group of specific phytoplankton, and the distribution in different groups were different, reversed-phase high-performance liquid chromatography was used to analyse the pigment composition of algae, and then a certain mathematical method was used to calculate the ratios of characteristic pigments to the Chl-a, by which the specific phytoplankton contribution to the total biomass could be indicated, and the abundance and composition of a population could be determined. By using high-performance liquid chromatography to detect target waters, eight characteristic photosynthetic pigments were detected, including Fuco, Allo, Viol, Zeax, Neox, Lute, Chl- $b$, and Chl- $a$. After analysis, we found that Fuco, Zeax, Allo, and Chl- $b$ were the most important characteristic photosynthetic pigments of the ultraphytoplankton in the Three Gorges Reservoir in 2014, 
it had also been found in earlier research (Chen et al., 2003) that the most important characteristic photosynthetic pigments of the ultraphytoplankton in marine were Fuco, Allo and Chl-b, however, Zeax and Lute were hardly found. The temporal and spatial differences in photosynthetic pigments indicated that the temporal and spatial distribution of the ultraphytoplankton populations ( $\mathrm{Li}, 2014)$, which said that it was more important to correspond to the community of Cryptophytes, Diatoms, Euglenophytes, Chrysophytes and other algae populations in the Three Gorges the ultraphytoplankton during 2014. However, the ultraphytoplankton in the marine are mostly Chlorophytes, Synechococcus, and Cyanobacteria (Li, 1995; Chen et al., 2003).

By using HPLC-CHEMTAX technical analysis, we showed that the changes of the ultraphytoplankton community structure in time and space were different. The dominant populations throughout the whole year were Euglenophytes, Diatoms, Cryptophytes, and Chrysophytes. Chlorophytes, Cyanophytes, and Dinoflagellates appeared in lower proportions. This is consistent with the results of Li (2014) and Liu et al. (2017). It shows that Euglenophytes, Diatoms, Cryptophytes and Chrysophytes are the dominant species of Ultraphytoplankton in the Three Gorges Reservoir. Special attention should be paid to February, April and June, as in these three months, dominant populations accounted for a large proportion, more than $50 \%$, easily leading to the outbreak of the ultraphytoplankton blooms. Therefore, a deeper observation and positioning investigation of these months could provide powerful data support for the Three Gorges Reservoir water environment improvement to change the ecological environment in the future. Previous reports (Huang and Huang, 2002) showed that Cryptophytes were the dominant phyla in water with high organic matter content and nutrient abundance. Similar phenomena were observed in the Three Gorges Reservoir area throughout the study period, and Cryptophytes were widely distributed in February, April, and August. Generally speaking, Diatoms prefer to live in an environment with high concentration of nitrates (Liu et al., 2012). According to the annual nutrient level, there was no significant difference in time, except for October, which may be the main reason for the lowest proportion of Diatoms in October. In 2014, the Euglenophytes occupied a dominant position, especially in the fall, present as high as $80 \%$. Most of them live in a fresh water rich in organic matter, which was an indicator of water pollution. The results showed that it is highly likely that ultraphytoplankton Euglenophytes blooms will occur in October.

The succession of phytoplankton is influenced by environmental factors. Based on earlier research about lakes and reservoirs, it was reported that in a poor nutrition system, $\mathrm{TP}<0.01 \mathrm{mg} / \mathrm{L}$ and $\mathrm{TN}<0.2 \mathrm{mg} / \mathrm{L}$, and in a rich nutrition system, TN $>0.5 \mathrm{mg} / \mathrm{L}$ and $\mathrm{TP}>0.02 \mathrm{mg} / \mathrm{L}$ (Peng et al., 2013). The minimum contents of TN and TP were 1.58 and $0.02 \mathrm{mg} / \mathrm{L}$, respectively, in 2014, which showed that the Three Gorges Reservoir area water environments all were of a rich nutrition system. The study of the typical tributaries upstream of the Three Gorges Reservoir area and streamwise nutritional status analysis made by Zhang et al.(2010), showed that the content of TN ranged from 0.58 to 1.67 $\mathrm{mg} / \mathrm{L}$, while the content of TP ranged from 0.005 to $0.133 \mathrm{mg} / \mathrm{L}$, the rich nutrition system was not changed. In contrast, the content of TN and TP in the Three Gorges branches and mainstream were significantly higher.

In this research, the relationship between the ultraphytoplankton community structure and environmental factors was not significant $(P>0.05)$ in October, showing that the ultraphytoplankton community structure was weak and affected by environmental factors in this month. The relationships between the ultraphytoplankton community structure and environmental factors were significant $(P<0.05)$ in the other 
five months. The analysis of RDA showed that the most important environmental factors impacting the ultraphytoplankton community structure included illumination (including illumination in air and underwater illumination), TP, and temperature (including air-temperature and water-temperature). These results were the same as another survey (Gonçalvesaraujo et al., 2012), which studied environmental factors influencing algae. Research (Alam et al., 2016) reported that the main limiting factors of phytoplankton growth were nutrients in the water. In these nutrients, TP was the most effective limiting factor to affect the growth of phytoplankton in fresh water, and because of its shape and concentration, can affect the metabolism process of phytoplankton cells. Studies (Sunda and Huntsma, 1997; Siegel et al., 2002) have shown that the correlation between the content of the Chl- $a$, algal cell density, and illumination, and the correlation between illumination and photosynthesis; the results confirmed that illumination was one of the controlling factors of algae growth. The reason was that sufficient illumination was the first condition of phytoplankton growth. The population structure, growth of phytoplankton, and succession of phytoplankton were directly determined by competition, adaptation, light resistance and light of the water environment. The study found that temperature was the most basic condition to control phytoplankton growth and those different groups of phytoplankton have different requirements of temperature (Zhang et al., 2010). In short, this paper discussed the relationships between the ultraphytoplankton distribution and environmental factors in the Three Gorges Reservoir and we should pay more attention to the effects of illumination, temperature and total phosphorus.

\section{Conclusions}

By using HPLC-CHEMTAX technical analysis, 8 types of characteristic photosynthetic pigments and 7 divisions of algae phyla of the Three Gorges Reservoir were quickly detected in 2014. The main types of the ultraphytoplankton in the reservoir were Euglenophytes, Chrysophytes, Cryptophytes, and Cyanophytes. During the study period, the Three Gorges Reservoir is a eutrophic water body, and the biomass of the ultraphytoplankton in the Hubei reservoir area was higher than that in the Chongqing Reservoir area. The characteristics of the structure and succession of the ultraphytoplankton community were mainly influenced by illumination, total phosphorus, and temperature. The results provided the basic data for the study of phytoplankton biodiversity and ecological environmental monitoring of the Three Gorges Reservoir.

Acknowledgements. We sincerely thank Dr. Yonghong Bi and the Three Gorges Reservoir Ecological Field Station for sampling. We thank the editors and anonymous referees for their professional help and comments on this manuscript.

Funding. This work was funded by the National Natural Science Foundation of China [No. 41171045]; funded the University Science and Technology Innovation Team Research Fund [No. T201504]; and was funded by the Research Fund of Hubei Normal University [No. 2014F014]. 


\section{REFERENCES}

[1] Agirbas, E., Feyzioglu, A. M., Kopuz, U., Llewellyn, C. A. (2015): Phytoplankton community composition in the south-eastern Black Sea determined with pigments measured by HPLC-CHEMTAX analyses and microscopy cell counts. - Journal of the Marine Biological Association of the United Kingdom 95(1): 35-52.

[2] Alam, R. Q., Benson, B. C., Visser, J. M., Gang, D. D. (2016): Response of estuarine phytoplankton to nutrient and spatio-temporal pattern of physico-chemical water quality parameters in Little Vermilion Bay, Louisiana. - Ecological Informatics 32: 79-90.

[3] Alvarez-Fernandez, S., Riegman, R. (2014): Chlorphyll in North Sea coastal and offshore waters does not reflect long term trends of phytoplankton biomass. - Journal of Sea Research 91(8): 35-44.

[4] Bonato, S., Breton, E., Didry, M., Lizon, F., Cornille, V., Lécuyer, E., Christaki, U., Artigas, L. F. (2016): Spatio-temporal patterns in phytoplankton assemblages in inshoreoffshore gradients using flow cytometry: a case study in the eastern English Channel. Journal of Marine Systems 156: 76-85.

[5] Chen, B. Z., Wang, L., Song, S. Q., Huang, B., Sun, J., Liu, H. (2011): Comparisons of picophytoplankton abundance, size, and fluorescence between summer and winter in northern South China Sea. - Continental Shelf Research 31(14): 1527-1540.

[6] Chen, J. X., Huang, B. Q., Jia, X. W., Hong, H. S., Xie, Y. H. (2003): Study on the structure of ultraphytoplankton community in Xiamen Sea by using photosynthetic pigment. - Marine Environment Science 22(3): 16-21 (in Chinese).

[7] Coclet, C., Garnier, C., Delpy, F., Jamet, D., Durrieu, G., Poupon, C. L., Mayer, M., Misson, B. (2017): Trace metal contamination as a toxic and structuring factor impacting ultraphytoplankton communities in a multicontaminated mediterranean coastal area. Progress in Oceanography 163: 196-213.

[8] Deng, C. G., Gong, L. (2007): A study on the development trend of eutrophication in the reservoir area of the Xia reservoir. - Chinese Journal of Agricultural Environmental Science 26: 279-282 (In Chinese).

[9] Glover, H. E., Prezelin. B. B., Campbell. L. (1988): Pico- and ultraplankton Sargasso Sea Communities: variability and comparative distributions of Synechococcus spp. and algae. - Marine Ecology Progress 49(1-2): 127-139.

[10] Gonçalvesaraujo, R., De Souza, M. S., Mendes, C. R. B., Tavano, V. M., Pollery, R. C., Garcia, C. A. E. (2012): Brazil-Malvinas confluence: effects of environmental variability on phytoplankton community structure. - Journal of Plankton Research 34(5): 399-415.

[11] Hallegraeff, G. F. (1981): Seasonal study of phytoplankton pigments and species at a coastal station off Sydney: importance of diatoms and nanoplankton. - Marine Biology 61: 107-118.

[12] Hu, J., Liu, X., Wang, L., Huang, B. Q. (2011): Qualitative and quantitative analysis of phytoplankton photosynthetic pigments marine science by reversed phase high performance liquid chromatography. - Marine Science 35(11): 19-28 (in Chinese).

[13] Huang, X. P., Huang, L. M. (2002): Spatial and temporal changes of inorganic nitrogen and activated phosphate content in the waters of the Pearl River estuary. - Journal of Applied Oceanography 21(4): 416-421 (in Chinese).

[14] Huang, Z. L., Li, Y. L. (2006): Water quality prediction and environmental capacity calculation of the Three Gorges Reservoir. - China Water Power Press, Beijing, pp. 1416 (in Chinese).

[15] Jeffrey, S. W. (1974): Profiles of photosynthetic pigments in the ocean using thin-layer chromatography. - Marine Biology 26: 101-110.

[16] Kong, F. X., Gao, G. (2005): Physiological mechanism of cyanobacteria bloom in large shallow eutrophic lakes. - Acta Ecologica Sinica 25(3): 589-595 (in Chinese). 
[17] Li, C. M., Huang, Z. L., Zhang, S., Chang, J. B. (2007): Algal bloom in the Three Gorges reservoir prediction. - Resources and Environment in the Yangtze River Basin 16(1): 1-6 (in Chinese).

[18] Li, J. Y. (2014): HPLC based on the analysis of photosynthetic pigments in the Three Gorges Reservoir super micro phytoplankton biodiversity research. - Hubei Normal University Master's Thesis, pp. 46-51 (in Chinese).

[19] Li, J. Y., Hou, J. J., Hu, J., Shi, X. Y. (2013): Application of chemical classification method in the study on the diversity of phytoplankton in fresh water. - Journal of Hubei Normal University 33(3): 46-50 (in Chinese).

[20] Li, J. Y., Hu, J., Hou, J. J., Zhou, T., Zheng, H. L, Liu, X. X., Bi, Y. H. (2015): A new method for the preparation of phytoplankton photosynthetic pigments by using pure culture algae. - Journal of Wuhan Textile University 28(6): 79-83 (in Chinese).

[21] Li, W. (1995): Composition of ultraphytoplankton in the Central North Atlantic. - Marine Ecology Progress Series 122(1-3): 1-8.

[22] Liu, X., Lu, X. H., Chen, Y. W. (2012): Temporal and spatial dynamics of the biomass of the algae in the northern part of Taihu Lake. - Journal of Lake Science 24(1): 142-148 (in Chinese).

[23] Liu, X. X., Li, J. Y., Bi, Y. H., Hou, J. J., Li, Y. T., He, Y. Y. (2017): Characterization of ultraphytoplankton pigments and functional community structure in Xiangxi Bay, China, using HPLC-CHEMTAX. - Journal of Freshwater Ecology 32(1): 1-16.

[24] Madhu, N. V., Ullas, N., Ashwini, R., Meenu, P., Rehitha, T. V., Lallu, K. R. (2014): Characterization of phytoplankton pigments and functional community structure in the Gulf of Mannar and the Palk Bay using HPLC-CHEMTAX analysis. - Continental Shelf Research 80(727): 79-90.

[25] Ning, X. R. (1997): Micro and ultra micro organisms in the ocean. - Journal of Marine Sciences 15(3): 60-64 (in Chinese).

[26] Pan, X. J., Liu, C., Zhu, M. L., Zheng, Z. W. Zou, X., Wan, C. Y. (2016): Impact of Three Gorges Reservoir impoundment and discharge on the phytoplankton community structure of Xiaojiang River. - Journal of Hydroecology 37(03); 42-48.

[27] Peng, R. C., Zhang, L., Zheng, Y. Z., Li, D. H. (2013): Seasonal succession of phytoplankton in response to the variation of environmental factors in the Gaolan River, Three Gorges Reservoir, China. - Chinese Journal of Oceanology and Limnology 31(4): 737-749.

[28] Sieburth. J. M. (1978): Pelagic ecosystem structure: Heterotrophic compartments of the plankton and their relationship to plankton size fractions. - Limnology \& Oceanography 23(6): 1256-1263.

[29] Siegel, D. A., Doney, S. C., Yoder, J. A. (2002): The North Atlantic spring phytoplankton bloom and Sverdrup's critical depth hypothesis. - Science 296(5568): 730-733.

[30] Silva, R., Negri, R., Lutz, V. (2009): Summer succession of ultraphytoplankton at the EPEA coastal station (Northern Argentina). - Journal of Plankton Research 31(4): 447458.

[31] Sunda, W. G., Huntsma, S. A. (1997): Interrelated influence of iron, light and cell size on marine phytoplankton growth. - Nature 390(6658): 389-392.

[32] Wasilowska, A., Kopczynska, E. E., Rzepecki, M. (2015): Temporal and spatial variation of phytoplankton in Admiralty Bay, South Shetlands: the dynamics of summer blooms shown by pigment and light microscopy analysis. - Polar Biology 38(8): 1249-1265.

[33] Wright, S. W. (1991): Improved HPLC method for the analysis of chlorophylls and carotenoids from marine phytoplankton. - Marine Ecology Progress Series 77: 183-196.

[34] Xiang, Y. C., Zhang, L. Y., Liu, G. Q., Zhou, N., Ren, J. (2014): Spatial temporal distribution of nutrients in the tributary backwater area of the Wanzhou section of the Three Gorges Reservoir. - Journal of Chongqing Three Gorges University 30(3): 4-9 (in Chinese). 
[35] Zhang, S., Liu, J. H., Li, L. L., Li, S., Xu, J., Gao, J. X. (2006): Distribution features of nutrient and phytoplankton in incipient Three Gorges Reservoir. - Environmental Science 27(6): 1056-1061.

[36] Zhang, S., Song, D., Zhang, K., Zeng, F. H., Li, D. G. (2010): Analysis of nutritional status in the upstream and backwater areas of the typical tributaries of the three gorges reservoir. - Journal of Lake Science 22(2): 201-207 (in Chinese).

[37] Zheng, B. H., Cao, C. J., Qin, Y. W., Huang, M. S. (2008): Characteristics and sources of nitrogen nutrients in the main reservoir of the Three Gorges Reservoir. - Environmental Science 29(1): 1-6 (in Chinese).

[38] Zhou, S., Tang, T., Wu, N., Fu, X., Jiang, W., Li, F., Cai, Q. H. (2009): Impacts of cascaded small hydropower plants on microzooplankton in Xiangxi River, China. - Acta Ecologica Sinica 29(1): 62-68. 